\title{
A STUDY ON PROPAGATION PROPERTY OF FATIGUE CRACK AT COMPOSITE WITH ANOTHER MATERIAL
}

\begin{abstract}
In this study, the fatigue crack propagation in composite material is investigated by experimental result. When another material exists at fatigue crack propagation in case of composite, the durability against fatigue crack is smaller or greater than in case of matrix without another material. As another material is composite material, it refers to steel or material. Another material influences the crack propagation. As the experimental results can be agreed with simulation data, all experimental data in this study are verified. These experimental and analysis results can be applied into real field effectively. The estimation of safety design and life will be of great value industrially.

Keywords: Fatigue crack propagation, Composite, Matrix, Another material, Crack propagation, Compact tension specimen
\end{abstract}

\section{Introduction}

Another material in composite materials influences the fatigue durability strongly [1-4]. The fatigue crack propagation depends on the critical stress at crack tip in material. Composite materials are composed of matrix and another material. Fatigue crack propagates slow or fast by another material with the different property near crack tip [5-9]. This paper investigates the fatigue property when the fatigue crack propagates between other materials. The fatigue crack propagations in composite materials are compared with the experimental results each other. These specimen geometries are investigated with compact tension (CT) specimens. The matrix is steel or brass, and another material is steel or brass. This study is carried out with the specimens of the matrix with another material and without another material. When another material exists near the fatigue crack in case of composite, the existence of another material influences the durability against the fracture due to crack propagation. As the experimental results can be agreed with simulation data, all experimental data in this study are verified. These experimental results can be applied into the real field effectively. By arranging this study result systematically about the crack propagation property due to the existence of another material, the material used at the high technical areas of automobile, aircraft and steel industry can be improved. The estimation of safety design and life(construction and nuclear power station, etc.) will be of great value industrially.

\section{Specimen and experimental condition}

The plates of steel and brass are used as the materials of specimens in this study. The compositions of materials at CT specimens are shown in Table 1. And the composition of BAG-7 filler to bond matrix and another material is shown in Table 2. Mechanical properties with bonding strengths for the materials used at CT specimens are shown in Table 3. Experimental conditions of fatigue loading for CT specimen are shown in Table 4 .

TABLE 1

Compositions of materials used at CT specimen

\begin{tabular}{|c|c|c|c|c|c|c|c|c|c|}
\hline \hline Material & \multicolumn{10}{|c|}{ Components (Wt\%) } \\
\hline \multirow{2}{*}{ Steel } & $\mathrm{C}$ & $\mathrm{Si}$ & $\mathrm{Mn}$ & $\mathrm{P}$ & $\mathrm{S}$ & $\mathrm{Cr}$ & $\mathrm{Ni}$ & $\mathrm{Mo}$ & $\mathrm{Cu}$ \\
\cline { 2 - 10 } & 0.15 & 0.22 & 0.63 & 0.015 & 0.009 & 0.01 & 0.05 & 0.01 & 0.03 \\
\hline \multirow{3}{*}{ Brass } & $\mathrm{Cu}$ & $\mathrm{Zn}$ & $\mathrm{Fe}$ & $\mathrm{Pb}$ & & & & & \\
\cline { 2 - 10 } & 63.9 & 35.87 & 0.12 & 0.11 & & & & & \\
\hline
\end{tabular}

TABLE 2

Composition of BAG-7 filler

\begin{tabular}{|c|c|c|c|c|c|}
\hline \multirow{2}{*}{ BAG-7 } & $\mathrm{Ag}$ & $\mathrm{Cu}$ & $\mathrm{Zn}$ & $\mathrm{Sn}$ & $\mathrm{Pb}+\mathrm{Fe}$ \\
\cline { 2 - 6 } & $55 \sim 57$ & $21 \sim 23$ & $15 \sim 19$ & $4.5 \sim 5.5$ & Rest \\
\hline
\end{tabular}

\footnotetext{
* DEPARTMENT OF METAL MOLD DESIGN ENGINEERING, KONGJU NATIONAL UNIVERSITY, CHEONAN-SI, REPUBLIC OF KOREA

** DIVISION OF MECHANICAL \& AUTOMOTIVE ENGINEERING, COLLEGE OF ENGINEERING, KONGJU NATIONAL UNIVERSITY, 1223-24 CHEONAN DAERO, SEOBUK-GU, CHEONAN-SI, CHUNGNAM 31080, REPUBLIC OF KOREA

\# Corresponding author: jucho@kongju.ac.kr
} 
TABLE 3

Mechanical properties for the materials used at CT specimen

\begin{tabular}{|c|c|c|c|c|}
\hline \hline $\begin{array}{c}\text { Material or material } \\
\text { combination (CT) }\end{array}$ & Steel & Brass & $\begin{array}{c}\text { Steel + } \\
\text { Brass }\end{array}$ & $\begin{array}{c}\text { Steel + } \\
\text { Steel }\end{array}$ \\
\hline Yield strength (MPa) & 493 & 225 & & \\
\hline Ultimate strength (MPa) & 607 & 343 & & \\
\hline $\begin{array}{c}\text { Modulus of elasticity } \\
(\mathrm{GPa})\end{array}$ & 103 & 39 & & \\
\hline Poisson's ratio & 0.36 & 0.29 & & \\
\hline Bonding strength (MPa) & & & 84 & 344 \\
\hline
\end{tabular}

TABLE 4

Experimental conditions of fatigue loading for CT specimen

\begin{tabular}{|c|c|c|}
\hline \hline Mean load $(\mathrm{N})$ & 3,920 & 14,700 \\
\hline Amplitude load $(\mathrm{N})$ & 2,940 & 7,840 \\
\hline Cycle rate $(\mathrm{Hz})$ & 10 & 20 \\
\hline
\end{tabular}

Fig. 1 shows the photos of 'Brass+Steel' CT specimen. This specimen has the matrix of brass bonded with another material of steel at experiment. CT specimen has the dimensions of $62.5 \mathrm{~mm}$ in width, $60 \mathrm{~mm}$ in length and $9 \mathrm{~mm}$ in thickness. Two types are manufactured in case of CT specimen: without the $7 \mathrm{~mm}$ holes (a), and with $7 \mathrm{~mm}$ holes (b) filled with cylinders of another material from that in the matrix specimen as three dimensional configurations shown in Fig. 2 [10]. At fatigue tester, two pins are installed at upper and lower pin hole with diameter of $12.5 \mathrm{~mm}$ on specimen. Fatigue loads are applied toward upper and lower direction respectively by upper and lower pins. Jigs are attached at both of upper and lower sides of specimen panel at fatigue tester. Through the attached jigs, fatigue tensile loads are applied toward the vertical direction on crack propagation.

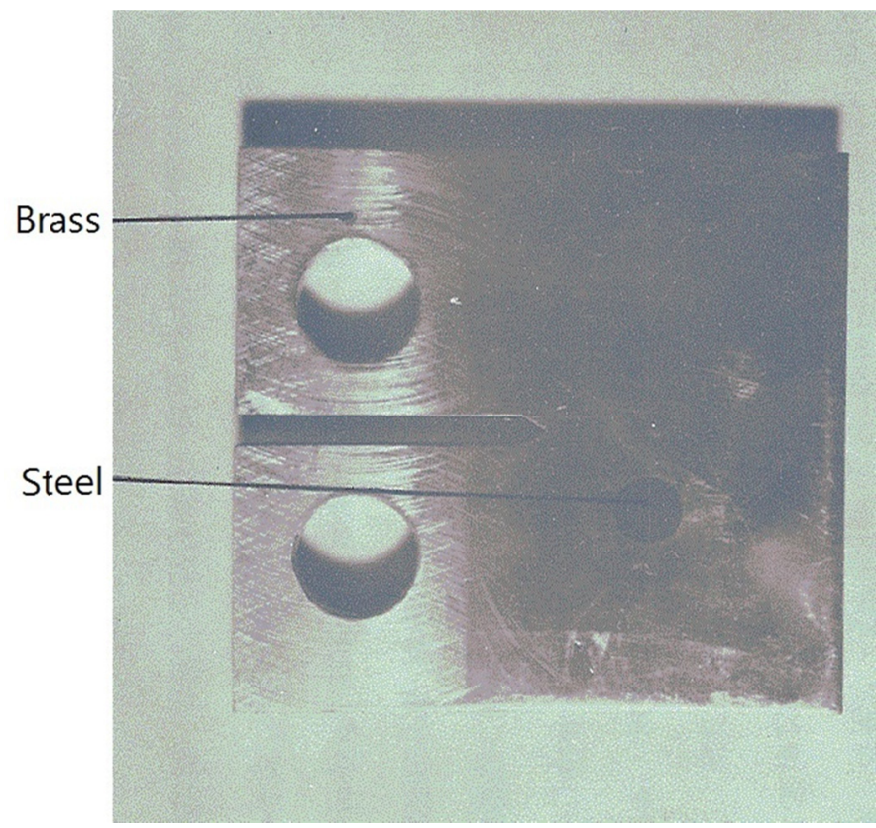

Fig. 1. Photo of CT specimen with the matrix of brass and another material of steel at experiment

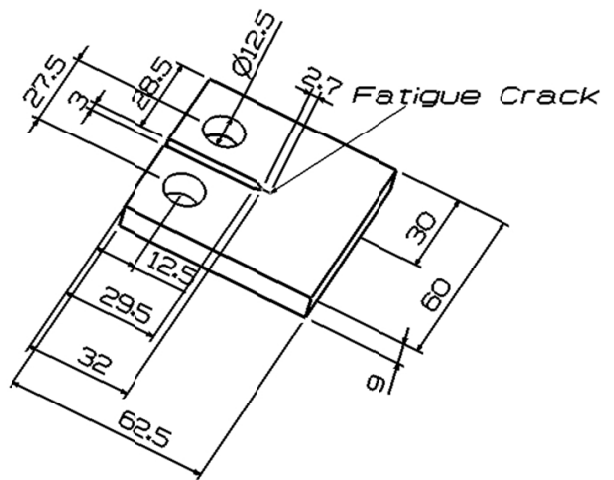

a)

(Unit : $\mathrm{mm}$ )

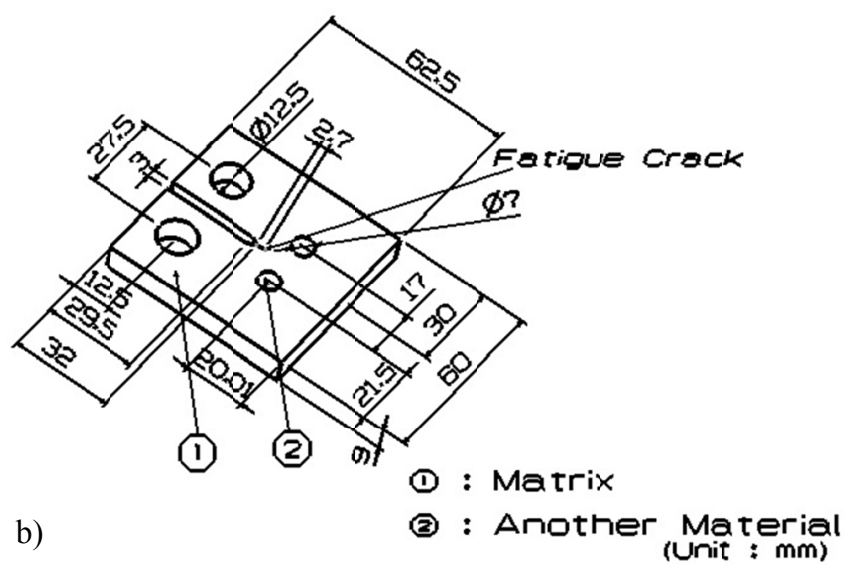

Fig. 2. Three dimensional configurations of CT specimens without holes (a) and with holes filled with another material (b)

\section{Study result}

Crack propagation rate $\left(\frac{d \mathbf{a}}{d N}\right)$ is denoted by applying Paris' law as Eq. (1).

$$
\frac{d \mathbf{a}}{d N}=C(\Delta K)^{m}
$$

a: Crack length (the length from the center of drilling hole to crack tip at CT specimen),

$N$ : Number of fatigue load cycles.

Material constants of $C$ and $m$ at CT specimens are calculated by using stress intensity factor ranges versus crack growth rates for $\mathrm{CT}$ specimens without hole [11]. In case of CT specimen, $C$ and $m$ are $2.00 \times 10^{-9}$ and 3.29. Experimental values of stress intensity factor ranges $(\Delta K)$ at fatigue test are calculated by Eq. (1).

Fig. 3 shows stress intensity factor ranges versus crack lengths at experiment in case of the specimens denoted 'Steel+ Steel' and 'Brass+Brass'[10]. The specimens of 'Steel+Steel' and 'Brass+Brass' are bonded with the same material of steel or brass inside the matrix of steel or brass respectively. In Fig. 3, these specimens are compared with the specimen with only the matrix of steel. The dash dot line or dot line is denoted as the specimen with only a matrix of steel or brass. In case of the specimen bonded with the same material of steel or brass inside the 
matrix of steel or brass, the stress intensity factor ranges become greater than only the matrix of steel or brass. By comparing the specimens of 'Steel+Steel' and 'Brass+Brass', the stress intensity factor ranges of 'Steel+Steel' specimen become greater than that of 'Brass+Brass' specimen. The stress intensity factor at the crack tip with the matrix of steel is greater than that of brass during fatigue crack propagation.

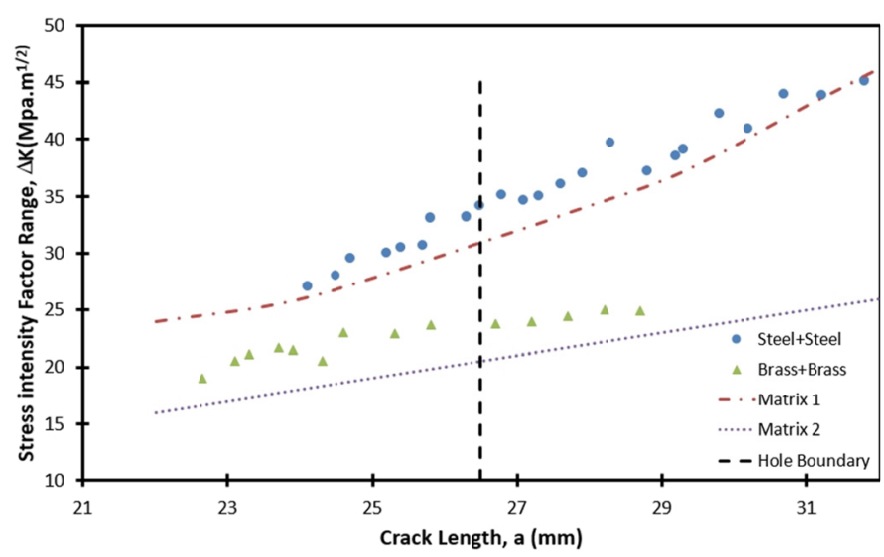

Fig. 3. Stress intensity factor ranges vs. crack lengths for compact tension specimens of 'steel+steel' and 'brass+brass' at experiment

Fig. 4 shows stress intensity factor ranges versus crack lengths by comparing analysis and experimental results in cases of 'Steel+Brass' CT specimen. The analysis condition is plane strain and $\operatorname{load}(\mathrm{P})$ is applied with peak to peak amplitude at fatigue loading. This specimen is bonded with another material of brass inside the matrix of steel. The solid line is denoted as the specimen with only a matrix of steel. At the beginning of fatigue crack propagation, the sub-crack as denoted by 'FEM 1' is initiated from the lower left side near hole. The configuration of sub-crack as denoted by 'FEM 2' is propagated from the lower left side into the upper right side near hole. So, it is shown that the sub-crack is propagated gradually from the lower left side into the upper right side near hole during the fatigue crack propagation.

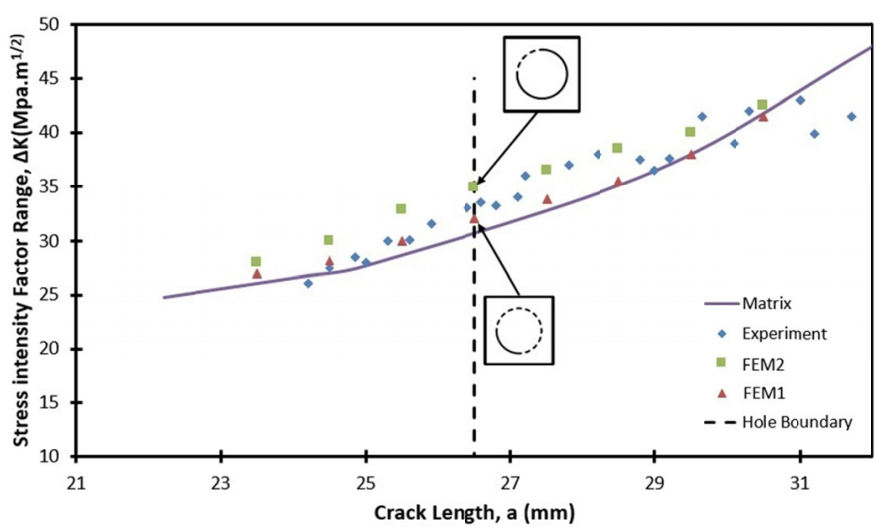

Fig. 4. Stress intensity factor range vs. crack length for compact tension specimen of 'steel+brass' at analysis and experiment

Fig. 5 shows stress intensity factor ranges versus crack lengths by comparing analysis and experimental results in cases of 'Brass+Steel' CT specimen. This specimen is bonded with another material of steel inside the matrix of brass. The solid line is denoted as the specimen with only a matrix of brass. At the beginning of fatigue crack propagation, the sub-crack as denoted by 'FEM 1' is initiated from the lower left side near hole. The configuration of sub-crack as denoted by 'FEM 2' is propagated from the lower left side into the upper right side near hole. So, it is shown that the sub-crack is propagated gradually from the lower left side into the upper right side near hole during the fatigue crack propagation.

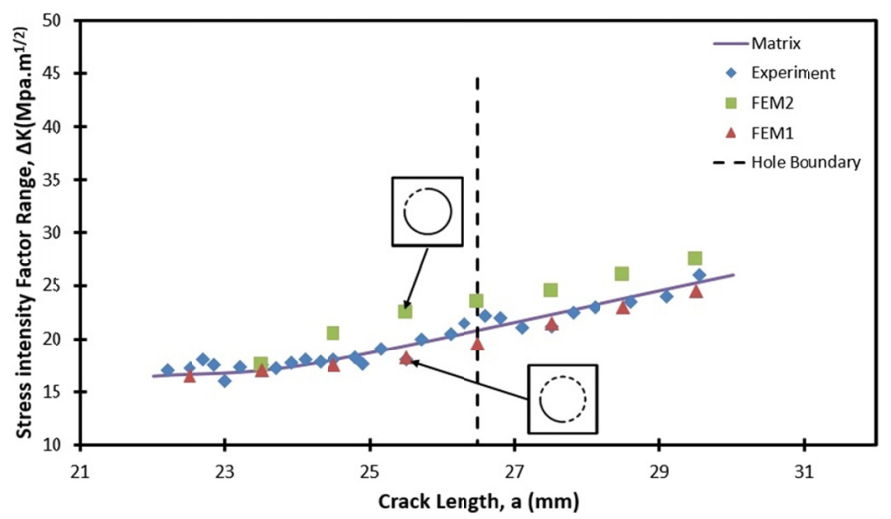

Fig. 5. Stress intensity factor range vs. crack length for compact tension specimen of 'brass+steel' at analysis and experiment

As shown by Figs. 3 and 5, the analysis results approach the experimental values. As the analysis results can be agreed with experimental data, all analysis data in this study are verified. These analysis and experimental results can be applied into real field effectively.

Fig. 6 shows the comparison of stress intensity factor ranges due to crack lengths in cases of the specimens of 'Steel+Brass' and 'Brass + Steel' at experiment. The stress intensity factor at the crack tip of 'Steel+Brass' specimen with the matrix of steel is greater than the specimen of 'Brass+ Steel' with the matrix of brass during fatigue crack propagation. So, the fatigue durability at the specimen with the matrix of steel is stronger than with the matrix of brass.

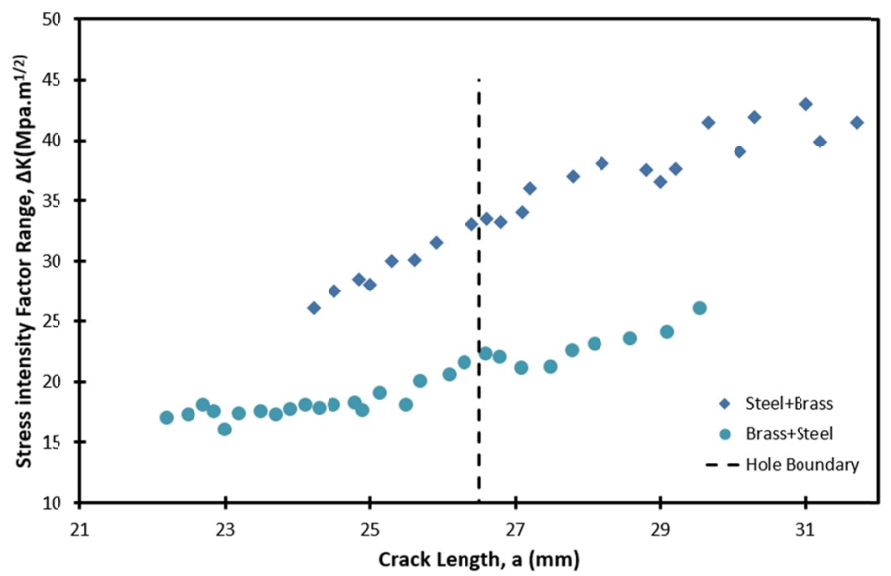

Fig. 6. Stress intensity factor ranges vs. crack lengths for compact tension specimens of 'steel+brass' and 'brass+steel' at experiment 


\section{Conclusion}

This study investigates the behavior of a fatigue crack propagating between steels or brasses at the composites of compact tension specimens. The experimental result is summarized as followings.

1. When the holes bonded with steels or brasses exist near the main fatigue crack symmetrically, the sub-crack is initiated from the lower left side near hole at the beginning of fatigue crack propagation. And it is propagated gradually into the upper right side during the fatigue crack propagation.

2. The stress intensity factor ranges bonded with another material become greater than only the matrix. During fatigue crack propagation, the sub-crack happens at the bonded part with another material. The stress intensity factor at crack tip with the matrix of steel is greater than that of brass during fatigue crack propagation. So, the fatigue durability at the specimen with the matrix of steel is stronger than with the matrix of brass.

3. As the analysis results can be agreed with experimental data, all analysis data in this study are verified. These analysis and experimental results can be applied into real field effectively. The estimation of safety design and life(construction and nuclear power station, etc.) will be of great value industrially.

\section{Acknowledgments}

This research was supported by Basic Science Research Program through the National Research Foundation of Korea (NRF) funded by the Ministry of Education, Science and Technology (2015R1D1A1A01057607).

This work was supported under the framework of international cooperation program managed by National Research Foundation of Korea(2016K2A9A2A06004689).

\section{REFERENCES}

[1] J.L. Grenestedt, Journal of the Mechanics and Physics of Solids 46, 29 (1998).

[2] E.D. Norman, Engineering Method for Deformation Fracture and Fatigue, Mechanical Behavior of Materials 2, 357 (1999).

[3] E.D. Francis, N.E. Prasad, C. Ratnam, P.S. Kumar, V.V. Kumar, International Journal of Advanced Science and Technology 27, 35 (2011).

[4] D.S. Prasad, A. Krishna, International Journal of Advanced Science and Technology 33, 51 (2011).

[5] D.S. Kwak, S.H. Kim, T,Y. Oh, International Journal of Precision Engineering and manufacturing 7, 30 (2006).

[6] S.S. Kim, M.S. Han, J.U. Cho, C.D. Cho, International Journal of Precision Engineering and manufacturing 14, 1791 (2013).

[7] M.S. Han, H.K. Choi, J.U. Cho, C.D. Cho, International Journal of Precision Engineering and manufacturing 14, 1395 (2013).

[8] J. Liu, Y. Wang, W. Li, International Journal of Automotive Technology 11, 659 (2010).

[9] L. Yongming, M. Sankaran, Engineering Fracture Mechcahanic 76, 2317 (2009).

[10] J.U. Cho, O.S., Lee, S.C., Kim, International Journal of Fracture 56, 299 (1992).

[11] J.U. Cho, L. Xie, C. Cho, S. Lee, International Journal of Fatigue 35, 23 (2012). 